
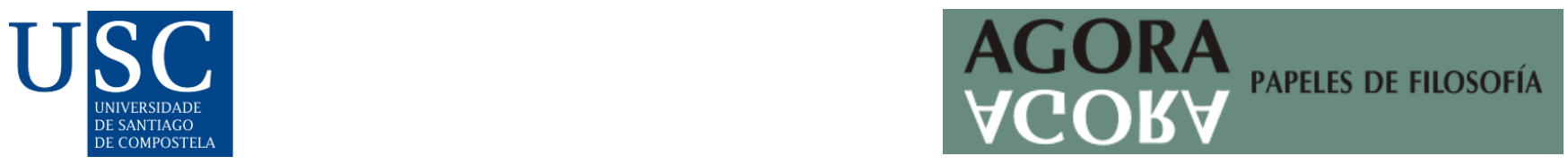

Agora. Papeles de Filosofía, 41(1), 2022. ISSN-e: 2174-3347

https://doi.org/10.15304/agora.41.1.7655

Recensiones

\title{
JAUME, Andrés Luis: Educación, Ciudadanía y Libertad, Sapere Aude, Asturias, 2019, 138p.
}

\author{
Pablo Vera Vega
}

Recibido: 22/04/2021; Aceptado: 03/05/2021

Puede que el posmodernismo vuelva a estar de moda. Así lo parece. Lo queer y lo tuitero, la vigencia del lenguaje inclusivo, la posverdad y los nuevos populismos, Veneno, Greta Thunberg, el deconstructivismo social, Samantha Hudson, El Mal Querer. Sí, sin duda, lo posmoderno ha salido nuevamente a la palestra. Y, repitiendo las guerras culturales de los ochenta y de los noventa, a lo posmoderno le responden sus contrarios. Vuelve el realismo crítico, esta vez de la mano de McIntyre, de Boghossian y de Ferraris; vuelve la reivindicación de un programa ilustrado, como al que nos invita la Filosofía Ciudadana de Quintanilla; y vuelve un cierto materialismo, como el de Erice en su Defensa de la razón. La obra que nos ocupa se inscribe en este paradójico momento. Educación, Ciudadanía y Libertad de Andrés L. Jaume es un compendio de ensayos sobre el presente que piensan y asumen, como veremos, lo posmoderno con el fin de reforzar la propuesta de la Ilustración.

Educación, Ciudadanía y Libertad se compone de tres capítulos a los cuales hay que agregarle, como de costumbre, una introducción. El primer capítulo, que lleva por título «De la educación y el conocimiento», consta de diez ensayos. El segundo, «Nacionalismo y libertad», se compone de cuatro ensayos, al igual que el tercero y último, «Meditación sobre Europa, otra vez».

En esta reseña, más que resumir contenidos, pretendo mostrar la tesis de fondo que estructura y da sentido, según creo, al texto en tanto que totalidad. Por ello, dado que la forma en que esta se despliega es una suerte de figura en espiral, se eludirá la organización explícita, por capítulos, para trazar el ir y venir de las ideas rectoras.

En Educación, Ciudadanía y Libertad nos encontramos con la constatación, aunque sea sólo como factum sociológico, de que, tal y como expuso Lyotard en La Condición Posmoderna, los grandes metarrelatos de la Modernidad se han desplomado (p. 17). Pero, ¿no implica esto una renuncia a la Ilustración? Asumir que ha acontecido la Posmodernidad es incompatible —o así lo creen muchos - con la reivindicación de un programa siquiera semejante al de la Ilustración. Si la Metafísica, en efecto, ha quedado destruida o, al menos, herida de muerte; si, como dice el autor, «lo esencial hoy es la inesencialidad» (p. 81), ¿cómo podremos no desistir de la solución iluminista?

La respuesta, la resignificación de lo Dado. Contra la dogmática de la razón, contra la fe vacía de la Ilustración, Jaume esgrime una cierta cordialidad con lo que el «transterrado» Sellars ya defendió en su apenas legible El empirismo y la filosofía de la mente. El carácter intrínsecamente imposible de lo Dado, es decir, su carácter mítico es lo que fuerza a Jaume a asumir una nueva condición para lo Dado. Esta vez lo Dado será interpretado desde parámetros si no hermenéuticos, casi 
hermenéuticos: «lo Dado es —nos dice el autor- únicamente la tradición» (p. 54). ¿No conforma acaso también la tradición una suerte de relato? Indudablemente, sí, pero la tradición ilustrada es una tradición que se sabe a sí misma como siendo tradición. En ella se desvela y vive, quizás con demasiada alegría, el relato en tanto que relato. El hechizo escatológico contra el que se pronunciaron los posmodernos desaparece, nos dice Jaume, «cuando la crítica se cierne sobre él» (p. 21). No deja de ser irónico: al relato que no se cree máximamente cierto lo sustituye la promesa utópica de una nueva Era de la Crítica.

Pero lo que salva a la razón ilustrada de ser defenestrada no es sólo el saberse como parte de un relato, no. En Educación, Ciudadanía y Libertad la razón ilustrada es defendida en tanto que el mejor de los relatos posibles. Ciertamente, en el libro no se esclarecen por completo los motivos de esta defensa. Aún así, podemos señalar dos tesis que, a modo de comentario, rigen este pensamiento.

La primera, de clara inspiración ética, alega que sólo hay un relato capaz de sostener de manera satisfactoria «la dignidad inalienable de cada quien» (p. 86) y que ese es, claro está, el ilustrado. No es por una revelación moral, ni por un salto de fe. La Ilustración es el único relato capaz de salvaguardar la dignidad humana porque «es el único que entiende que la verdad se busca y quizás no se halla jamás». El relato ilustrado asume, nos dice Jaume, que «su verdad es la no verdad» (p. 21). Consecuentemente, no puede más que ser un relato laico «porque nadie está en posesión de una última palabra que dé con un punto final en la discusión» (p. 19).

Caracterizado de esta forma el relato de la ilustración puede parecer el de una razón si no nula, sí escéptica. Sin embargo, este escepticismo no es imposibilitante, más bien al contrario: «en la razón moderna se está, pero no de cualquier manera, sino confortablemente asentada en un escepticismo burgués que, cuando despierta, ejerce la crítica de la propia crítica, que es en lo que cabe cifrar esa empresa autocorrectiva de la racionalidad» (p. 118). La capacidad autocorrectiva de la racionalidad ilustrada es, según creo, la segunda tesis. Y esta tesis, por cierto, sigue debiéndole mucho a la Escuela de Pittsburg.

El relato ilustrado favorece la autocorrección porque asume la absoluta incompletud con la que se nos presenta la verdad a la vez que también afirma su carácter perspectival. Por consiguiente, todo conocimiento que pretenda ser verdadero será siempre corregible. Eso sí, será corregible desde sí mismo: será el conocimiento y exclusivamente el conocimiento lo que corrija al conocimiento y bajo ningún concepto podrá ser otra instancia distinta la que lo haga.

La defensa del relato ilustrado, aunque sea ahora con plena consciencia de que es simplemente un relato más, sirve para tratar temas tan dispares como el de la cristiandad, el gusto, el nacionalismo, Europa, la libertad, la educación estética, la tauromaquia, la idea de trascendencia, la ciudadanía, etc. Esta pléyade de problemas se plantea siempre desde la perspectiva aquí sugerida. El tono, el estilo y, por supuesto, el punto de vista mucho le deben a Sellars, a Kant, a Foucault y a Lyotard, pero no menos a Ortega y a Marías, cuyo pensamiento, por cierto, reivindica en diversas ocasiones.

Ya para finalizar, recomiendo la lectura de Educación, Ciudadanía y Libertad. A buen seguro encontrará el lector interesantes sugerencias en la muy notable originalidad de la síntesis de Posmodernidad e Ilustración que subyace al texto y en las ricas reflexiones que se siguen de ella. 